\title{
Research on the Validity Test Method of Teaching Based on ARCS Motivational Design Model
}

\author{
Wen Wang \\ Binzhou Polytechnic, 256603, Binzhou, China \\ w_ang_wen@126.com
}

Keywords: ARCS motivation; design model; quantitative analysis; t-test; performance analysis; effective degree

\begin{abstract}
Learning motivation is a promotion of learning impetus, and motivation model of ARCS learning is to inspire students' learning motivation. This research is to explore the effectiveness of English research ascension in the college English teaching. The research carries out a semester strategy intervention to the experimental group of the ARCS model. The author designs the teaching motivation from the the four elements ---note, relevance, faith and satisfaction. At the same time, according to the comparison between the experimental group and the control group of ARCS motivation, it carries out English scores before and after the test measurement, at last ,it makes a quantitative analysis of the datas. In addition, the researchers will attend a lecture biweekly for experimental group and control group to observe and record students classroom performance, and combine with the t-est method to test its changes and differences. The results of the research show that ARCS motivation design model can effectively improve college students' English research and classroom performance.
\end{abstract}

\section{Introduction}

"How can let the students those who don't want to learn be interested in learning?"," How to effectively maintain students' learning motivation?" These problems is not a simple easy question to answer for teachers in the world. As is known to all, learning motivation and interest is the condition to promote research, therefore, a lot of education workers tried different ways to improve students' interest in class, so as to achieve the purpose of improving students' grades[1]. After years of theoretical and practical studies, the American scholar Keller puts forward ARCS motivation design model to help the education workers to solve the problem that how to arouse and maintain students' learning motivation meting on the teaching practice[2]. A represents Attention, $\mathrm{R}$ represents Relevance, C represents Confidence, S represents Satisfaction. From four aspects, Motivation design theory puts forward a feasible effective strategy to improve students' learning motivation . Keller will make ARCS model of the four aspects as a whole, no primary and secondary division, the lack of any one aspect can make learners lose learning motivation(YangKai cheng, 2001)[3].

Keller puts forword the ARCS motivation design model which is based on behaviorism, cognitivism and humanism, absorbs the essence of the three learning theory, and developed it to be the motivation theories which not only pay attention to the students' intrinsic learning motivation,but also emphasize the effective and practice value of the external learning motivation .

LuoZheng, GuoDejun, YuanYanli and ZouHengpu (2000) adopted the combining methods of the quantitation and qualitation to make a effectively research of the ARCS motivation design model in our middle school language classroom teaching. The results show that ARCS motivation design model can be effectively adopted by the middle school chinese teachers, and its effectiveness show some of the grade difference[4]. It can effectively improve the junior middle school students learning motivation and learning performance, and improve the poor students' learning performance; In high school chinese teaching, its validity is not obvious.

Zhang Jianfeng (2008)[4]studied the function of the ARCS model for college English listening learning effect, and pointed out that the students' motivation of initiatively training English listening rest with the recognition of the value of behavior, and is the result of the interaction of the internal 
and external motivation. ARCS model can arouse and maintain students' listening motivation and improve listening performance.

Gao Chunmei (2006) [5] used the quantitative analysis method to research the students' English learning motivation which belongs to the reformed college English teaching[5]. The research results show that, ARCS motivation design model of the attention, relevance, confidence and satisfaction, the four aspects have degrees influence in students' learning motivation, especitially, it has a guiding significance for the reformed education which pays attention to the listening and speaking ability training in college English teaching.

The effectiveness of the ARCS motivation design model has a lot of valid teaching practice in foreign countries (Keller and Suzuki, 1988) [6], but in our country, there is a little research on the effectiveness and applicability of the ARCS motivation design model, and only a handful of some education scholars who are engaged in higher vocational education and middle school education make the preliminary research, and which involves mainly in politics, chinese, computer and medical care professional. Therefore, the effectiveness of the ARCS motivation design model to our country non-English major college students' English research s' ascension needs to be inspection.

\section{Research methods and stages}

We make a quantitative analysis and discussion on the data which are collected in the process of the experimental to inspect the effectiveness of the ARCS motivation design model for the nonEnglish major college students' English teaching[6]. The research involved the comparison with the English test scores of the non-English major students in experiment before and after the experiment.

In this research, ARCS model for students' English grade influence will be inspected by the researchers, who combined the university English CET-4 test with the textbook knowledge, developed the test roll. For one thing, the test examines the students' integrated English ability for another thing, it inspects the textbooks knowledge mastering of the students.

TABLE I. TEACHING IN MOTIVATION DESIGN - ARCS MODEL

\begin{tabular}{|l|l|l|l|}
\hline Model elements & \multicolumn{3}{|c|}{ Teaching in motivation design } \\
\hline NoteS & Waking up the perception & Excitation explore & changes \\
\hline Relevance & Familiared & Goal orientation & Motivation matching \\
\hline Confidance & Expecting success & Challenge situation & Attribution way \\
\hline Satisfaction & Natural results & Positive results & justice \\
\hline
\end{tabular}

\section{A. Research methods}

This research will adopt experiment design method, and then select the mechanical major freshmen class as the experimental group, the computer professional first grade class as control group. The two groups are not English major freshmen, and the number of the two classes students each is 30. Through the experimental group in college English teaching in the process of implementing a semester ARCS model strategy, this research will inspection: whether the ARCS motivation design model can effectively improve the non-English major students' English learning performance.

In addition, under the condition of having no interference to the experiment group students' normal classes, the researchers will biweekly attend a lecture in the experimental group and control group to see the two classes of students' class performance for changes and differences.

This research hypothesis: the experimental group and the control group exist differences in English results.

T-test is used $\mathrm{T}$ distribution theory to infer the differences occur probability, so as to compare whether the two average difference is obvious.

T-test steps: making a null hypothesis $\mathrm{H} 0: \mu 1=\mu 2$, that's assuming that there is no obvious differences between the two population mean.

Step 1:Calculation statistics $T$, for different type of problems choose different statistic calculation method;

(1)If it wants to judge the difference level between a general of the s sample average and the overall average, the calculation statistic $\mathrm{T}$ formula is[7]: 


$$
T=\frac{\bar{X}-\mu_{0}}{\frac{S}{n-1}}
$$

(2) If it wants to judge the difference degree between the two mean sample groups, the calculation statistic $\mathrm{T}$ formula is[8]:

$$
T=\frac{\bar{X}_{1}-\bar{X}_{2}}{\sqrt{\frac{\sum x_{1}^{2}+\sum x_{2}^{2}}{n_{1}+n_{2}-2}} \times \frac{n_{1}+n_{2}}{n_{1} \times n_{2}}}
$$

Step 2: According to the freedom degree $\mathrm{df}=\mathrm{n}-1$, check $\mathrm{T}$ value table, and find out the regulation of $\mathrm{T}$ theoretical value ,then make a comparison. The obvious differences level of the theoretical value is 0.01 magnitude or 0.05 magnitude. Different freedom degrees of the obvious theoretical value recorded as $\mathrm{T}(\mathrm{df}) 0.01$ and $\mathrm{T}(\mathrm{df}) 0.05$.

Comparing the calculated $t$ value with the theoretical $\mathrm{T}$ value infer the occurrence probability .In the table, according to the obvious relevence table of the given $\mathrm{T}$ value and the difference to make a judgment.

TABLE II. THE OBVIOUS RELEVENCE TABLE OF THE GIVEN T VALUE AND THE DIFFERENCE

\begin{tabular}{|c|c|l|}
\hline $\mathbf{T}$ & $\mathbf{P}$ & \multicolumn{1}{c|}{ Difference obvious degree } \\
\hline$T \geq \mathrm{T}(d f) 0.01$ & $P \leq 0.01$ & Difference is very obvious. significant \\
\hline$T \geq \mathrm{T}(d f) 0.05$ & $P \leq 0.05$ & Obvious difference \\
\hline$T<\mathrm{T}(d f) 0.05$ & $P>0.05$ & Difference is not obvious. \\
\hline
\end{tabular}

According to above analysis, combining with the specific circumstances, we can make a conclusion.

B. Research stages

The research is divided into three stages[9]:

Stage 1.Former measurement: an English test between the two experimental classes before the experiment.

Stage 2.Experimental intervention: in college English teaching implement a semester ARCS model strategy intervention in the experimental group, and regularly observe the students performance in the two classes .

Stage 3.After measurement: an English test between the two experimental classes after the experiment.

\section{The experimental results}

The two classes former and after measurement English results of the respectively independent sample t-test show that mechanical class and computer class before the English test does not exist obvious difference $(\mathrm{t}=1.382, \mathrm{p}=0.176>0.05)$, and the difference level of the two classes after measuring English scores is obvious $(\mathrm{t}=3.867, \mathrm{p}=0.019<0.05)$. Former and after test measuring English t-test results shows that ARCS motivation design model can effectively improve students' college English learning performance[10].

TABLE III. FORMER ENGLISH TEST MEASURING ---T-TEST (INDEPENDENT SAMPLES TEST)
\begin{tabular}{|c|l|l|l|l|l|}
\hline \multirow{2}{*}{$\begin{array}{c}\text { Levene's Test for } \\
\text { Equality of Variances }\end{array}$} & \multicolumn{3}{|l}{ t-test for Equality of Means } \\
\cline { 2 - 6 } & $\mathrm{F}$ & Sig. & $\mathrm{t}$ & $\mathrm{df}$ & Sig. \\
\hline $\begin{array}{c}\text { English score Equal variances } \\
\text { Assumed Equal variances } \\
\text { not assumed }\end{array}$ & 0.049 & 0.792 & 1.382 & 58 & 0.176 \\
& & & 1.382 & 57.952 & 0.176 \\
\hline
\end{tabular}

$(p=0.176>0.05$ show: there is no obvious differences between the experimental group and the control group) TABLE IV. AFTER ENGLISH TEST MEASURING ---T-TEST (INDEPENDENT SAMPLES TEST)

\begin{tabular}{|c|l|l|l|l|l|}
\hline \multirow{2}{*}{} & \multicolumn{2}{|c|}{$\begin{array}{c}\text { Levene's Test for } \\
\text { Equality of Variances }\end{array}$} & \multicolumn{3}{|c|}{ t-test for Equality of Means } \\
\cline { 2 - 6 } & $\mathrm{F}$ & Sig. & $\mathrm{t}$ & $\mathrm{df}$ & $\mathrm{Sig}$. \\
\hline $\begin{array}{c}\text { English score Equal variances } \\
\text { Assumed Equal variances } \\
\text { not assumed }\end{array}$ & 2.314 & .562 & 3.867 & 58 & .019 \\
& & & 3.867 & 57.952 & .019 \\
\hline
\end{tabular}


From the Figure 1,English achievement-test results before and after the test analysis,we can see, before test and after testing, the F, Sig., $t$ value have change, and the df value without change. F value increased from 0.049 to 2.314, and t value also appears obvious increasing from 1.382 to 3.867. It also shows the difference of the two classes'English scores after measuring reaches obvious level.

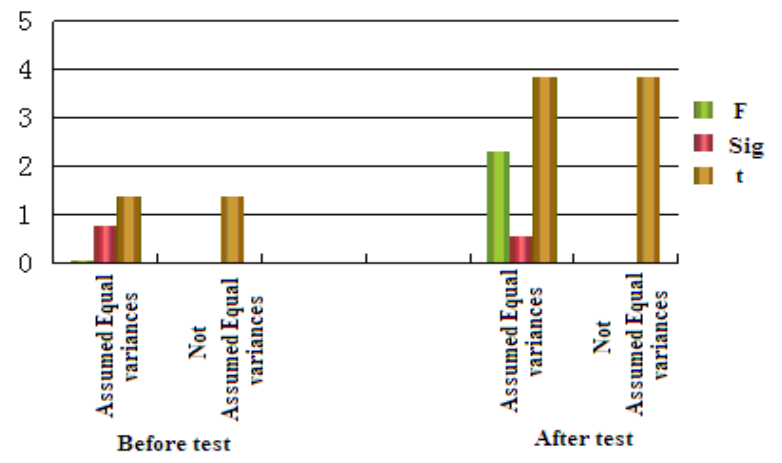

Figure 1. The inspection and analysis of the English achievement-test results before and after test

Through the above analysis, this paper puts forward the teaching strategy which is based on the ARCS motivation mode is effective and also shows the use of ARCS motivation mode for teaching English helpful to improve students' motivation level and the academic achievement, and it is consisten to the quasi research results.

\section{Discussion}

Learning motivation and effort degree of ascension will affect students' learning achievement. The research shows that, when a student can focus attention to accept knowledge output and can actively participate in interaction in the classroom, and under the help of the teacher finds the usefulness and value of research, in the teachers' positive encouragement and timely, positive feedback improve confidence and satisfaction, the improvement of learning motivation will make his or her learning efficiency higher, research performance also be improved obviously. Only unifying the ARCS motivation design model of the attention, relevance, confidence and satisfaction these four aspects, supplement each other, can really inspire and sustain students' learning interest and motivation, and therefore improve English learning performance.

\section{A.Attention}

Whether a class is success lies in the teacher can attract the attention of students. If a student is casual and lax attention in the classroom, thus students can't successfully receive teachers' knowledge output. How to attract the attention of students? First of all, the teacher can organize students actively participate in class activities, it can active the student thought, promote students' thinking, and active classroom and pay atmosphere[11]. As a teacher, he or she should be based on the teaching goal and content, and pay attention to the variety of the teaching method in own teaching link . For example, a scenario opusculum design, spell words competition, team debate, etc. Various kinds of activities fully mobilize the enthusiasm of the students. In addition, as a teacher can properly use their humor sense to active classroom atmosphere. Teachers can properly seize the "small accident" to make humors, so as to active classroom atmosphere immediately, student's fatigue also immediately lifts no trace.The next research can successfully fisnish in the interaction between teachers and students.

\section{B. Relevance}

Relevance refers to the useful value of learning content for learners (Keller, 1983) [7]. "Application" is all the learners pursuit goals, when students find the knowledge in books can guide work, life and research in practice, they will be more actively to learn. On the contrary, if the students feel the content what they have learned have no use, so as to they will lack learning motivation, gradually lose interest in learning, and learning score will not be good.

The value of learning content is often difficult to find for students, therefore, the teacher should establish relevant learning content in their teaching, and guide students to find the usefulness of learning content, namely value. Teachers should let students understand in the first class: English learning is not an end in itself, its final purpose is to let it become a useful and powerful tools in students' future development . Teachers should pay attention to the relevance design, the research relevance should be established basedyl on the students existing knowledge level. If you don't pay 
attention to student's existing English level, simply pursuing high standard ,strict requirements, the result can only run in the opposite direction with the ultimate goal, tapering off.

\section{C.Confidence and satisfaction}

Confident students who have active thinking, keen observation, rich imagination; On the contrary, not confident students who have poor self-evaluation and research initiative. How can the teachers help students to establish confidence? Teachers should make students understand that success is based on the efforts, and in the teaching process often give actively encourage and suggest that let them know that even small progress is worth being happy, and the small progress can step by step be accumulated to be a great progress and finally achieve their goals.

When students in English learning achievement have made progress, they will have a sense of accomplishment, and this kind of accomplishment often become power to make greater progress, improve students' learning satisfaction, thus forming a kind of benign cycle [12-14].

\section{Conclusion}

This research combines ARCS motivation design mode with college English teaching practice, including the use of English test paper combining the textbook knowledge and extra-curricular knowledge, and comprehensively test students' comprehensive ability. The improvement of students' English test scores adequtely reflects the validity of the ARCS model.

In this research, through the strategy for the ARCS motivation design model implements a semester, and the results show that: ARCS motivation design model can effectively improve the nonEnglish major students' English learning achievement and classroom performance. It is worth widely implementing and promoting in college English teaching.

\section{References}

[1] Yang Kaicheng, Li Xiulan, Fan Wenqiang. Establishing the on online learning system based on the ARCS motivation model . Electrochemical education research, 2001(3) : 46-49.

[2] Keller, J. M. Development and use of the ARCS model of motivational design. Journal of Instructional Development, 2010(3):23-27

[3] Luo Zheng, Guo Dejun, Yuan Yanli, Zou Hengpu. The valid analysis of the ARCS motivation design model used in the middle school language classroom teaching. Journal of Capital normal university: social science edition, 2010 (5) : 106-111.

[4] Zhang Jianfeng. The application of the ARCS model motivating college English listening learning motivation. Technology and innovation management, 2010 (4) : 28-31.

[5] Gao Chunmei. The research of college students' English learning motivation after the college English teaching reformed . Journal of zhejiang university of commerce, 2011(4) : 78-82.

[6] Keller, J.M. \& Suzuki, K. Use of the ARCS Motivational Model in Courseware Design. In D.H. Jonassen (Ed.), Instructional Design for Microcomputer Courseware . New York: Lawrence Erlbaum Associates, 2008:345-348.

[7] Keller, J.M. (1983). Motivational design of instruction. In C.M. Riegeluth (Ed.), Instructional design theories and models (pp. 383-434). Hillsdale, NJ: Lawrence Erlbaum.

[8] Guo Dejun, Wang Ling, Li Ling. ARCS motivation design patterns. Journal of capital normal university (social science edition), 2000 (5) : 91-97.

[9] Wang Haichun. ARCS motivation design patterns in classroom teaching . Chengdu air vocational and technical college journal, 2010 (4):78-81.

[10] Zhang Zuxin. How to integrate the teaching principle of motivation in design process - the talking about John M keller professor's motivation system theory.Journal of open education research, 2011(2) : 9-12.

[11] Fu Xinyou. The application of ARCS motivation strategy in higher vocational English teaching . Journal of jiangsu radio and TV university, 2010 (3) : 90-92.

[12] Li Jinyu. The research and application of ARCS motivation mode in higher vocational college English reading teaching. Science and education guide, 2010 (9) :47 - 48.

[13] Chen Xiuqiong. The constructing of computer culture basis teaching mode based on the theory of ARCS . Journal of sanming college,2011 (6) : 221-224.

[14] Peng Li. The application of ARCS motivation design teaching mode in university language teaching . Education technology guide,2007(9) : 17-18. 